\title{
A textual perspective on referential metonymy
}

Una perspectiva textual

sobre la metonimia referencial

Lise Fontaine

Cardiff University, Centre for Language and Communication Research fontainel@cardiff.ac.uk 


\section{Abstract}

Within the field of Systemic Functional Linguistics (SFL), metonymy has not attracted much attention in comparison to other approaches such as cognitive linguistics where it has a more important place. This paper aims to examine referential metonymy from the perspective of the SFL framework and to offer a theoretical argument for how it can be accounted for within existing SFL constructs. The main idea pursued here is that referential metonymy, as a type of indirect encoding of meaning, might be best accounted for in terms of incongruency. Bringing together perspectives from outside SFL and drawing on Martin's (1992) IDENTIFICATION system, I make the case for referential metonymy to be interpreted in terms of textual grammatical metaphor due to the atypical referential mappings and the blended semantics construed by these expressions.

Keywords: metonymy, referring expressions, congruence, stratification, grammatical metaphor

\section{Resumen}

Dentro del campo de la Lingüística Sistémico-Funcional (LSF), la metonimia no ha suscitado mucho interés en comparación con otros enfoques tales como la lingüística cognitiva, en la que ocupa un lugar prominente. El presente trabajo tiene por objeto examinar la metonimia referencial desde la perspectiva de la LSF y ofrecer un razonamiento teórico sobre la manera de estudiar este fenómeno basándose en constructos existentes dentro de esta teoría. La idea que se intenta ilustrar es que la metonimia referencial, como un tipo de codificación indirecta de significado, puede explicarse mejor en términos de incongruencia. Mediante la integración de perspectivas externas a la LSF y retomando el sistema de IDENTIFICACIÓN de Martin (1992), se propone que la metonimia referencial sea interpretada en términos de metáfora gramatical textual debido a la atipicidad de los mapeos referenciales y a la integración semántica que construyen estas expresiones.

Palabras clave: metonimia, expresiones referenciales, congruencia, estratificación, metáfora gramatical 


\section{Introduction}

In the well-known example, the ham sandwich is waiting for his check (Lakoff \& Johnson, 1980), it is clear that ham sandwich denotes a class of food but also that the ham sandwich is used by the speaker to refer to a person and that this expression is co-referential with his later in the clause. This type of metonymy is termed referential metonymy. Metonymy is often characterized in terms of some ad hoc description carrying an associative or relational meaning with respect to the intended discourse referent. While relatively more work has been done on metonymy from a cognitive perspective (e.g., Langacker, 1999; Croft, 2002), very little work has considered its textual role or its place in ongoing discourse (although see Denroche, 2018). Within the field of Systemic Functional Linguistics (SFL), metonymy has not attracted much attention. It was discussed briefly by Halliday and Matthiessen (1999: 225) as a type of figure of speech where it is treated as a type of expansion. However, no detailed account has yet been offered as to how it fits into the overall framework, especially in terms of textual semantics. Since, as Dancygier (2009: 168) suggests, referential metonymy relies heavily on contextual knowledge, we would expect some trace of this in text. The main aim of this paper is to examine referential metonymy from the perspective of the SFL framework and to offer a theoretical argument for how it can be accounted for within existing SFL constructs. The motivation for this is novel in that it is based on the idea that referential metonymy, as a type of indirect encoding of meaning, might be best accounted for in terms of incongruency. I make the case for referential metonymy to be interpreted in terms of grammatical metaphor.

This paper will first provide an overview of referential metonymy, drawing out some of the key features of its use and gleaning from this its nature as a fundamentally textual resource. Section 3 and section 4 provide the foundation for the main theoretical arguments that are developed later in section 5. Section 3 presents Martin's IDENTIFICATION system (1992), providing a discourse se- 
mantics perspective on referring expressions. This is an important perspective for understanding the implications of the stratification of content into semantics and lexicogrammar. Section 4 reviews the key concepts that ensue from stratification, namely congruence, construal and grammatical metaphor. Halliday's key concept of semantic junction (Halliday, 2006: 360) is developed towards an account of referential metonymy in terms of how it allows the construal of multiple meanings. The fundamental points from these two sections are brought together in section 5 where the main theoretical position of this paper is presented. The argument made here is that referential metonymy may be best viewed as textual grammatical metaphor due to the atypical referential mappings and the blended semantics construed by these expressions. The paper concludes with a brief summary and important directions for taking this research further.

\section{A brief overview of referential metonymy}

Hurford, Heasley, and Smith (2007: 339) offer the following explanation of the ham sandwich example:

In the particular context in which this sentence would be uttered, presumably a café or restaurant, the person uttering the sentence would know that there was a close relationship between the thing ordered and the person who ordered it. Because this relationship is so obvious in the context, it is permissible to refer to the person by what he ordered. As a matter of fact, this might be the preferred way of referring to the person, because the people who wait on customers in a diner typically don't learn the names of their customers, but they are well aware of what their customers ordered.

Here we find context as one of the principal motivating factors in the use of referential metonymy. Within SFL, language is viewed 
as embedded within context, both situational and cultural context. Each of these is defined by Martin (1992: 121) as follows:

- Context of situation: "relevant information that can be perceived (seen, heard, felt, tasted, smelled), including text."

- Context of culture: "relevant information which cannot be perceived, but which can be assumed because of shared knowledge among interlocutors deriving from their membership in some definable community."

In the ham sandwich example, we can infer, as Hurford, Heasley and Smith (2007) seem to do, that the identification of the intended referent is anchored in the context of situation, i.e., the person who is waiting to pay is visible to the addressee. However, this is not always the case and we find examples where context of culture suffices, as illustrated in example (1), where the metonymic expression is underscored. It is worth noting that had the noun customer been used instead of table, it would not be an instance of metonymy.

(1) hey i am working in a restaurant and recently one of my tables left without paying. I was given a warning but told that next time the difference will be taken from my wages. I know that other employees have to pay for walkouts regularly. Is this legal?

(Sketchengine enTenTen15) ${ }^{1}$

As Lakoff (1987: 78) explains, metonymy can be thought of as "a 'stands-for' relation". Barcelona (2019: 171) provides a broad but very useful definition, highlighting the importance of a pragmatic function:

1 For details of SketchEngine, an online resource for research using corpus linguistics, see Kilgarriff, Baisa, Bušta, Jakubíček, Kovár, Michelfeit, Rychlý and Suchomel (2014). 
Metonymy is an asymmetric mapping of a conceptual entity, the source, onto another conceptual entity, the target. Source and target are in the same frame and their roles are linked by a pragmatic function, so that the target is mentally activated.

Metonymy is not strictly a feature of language. Barcelona describes it as an "essentially conceptual process, which is reflected in various types of semiotic modes, particularly human language (both oral and sign language), but also gesture, art (music, painting, sculpture), etc." (2019: 168). This conceptual aspect is pervasive in discussions of metonymy. Slabakova, Cabrelli, and Kyun (2016: 176) describe metonymy as "a well-established mental process, whereby the mention of some entity (activity, person, thing, time period, etc.) is interpreted to stand for a related entity". This can be seen in example (1), taken from an online forum for those seeking legal advice related to employment, where it is clear that the speaker is not specifying a particular table as the intended referent but rather a person, a customer at a restaurant. It should also be clear from this example that, as Bowerman (2016: 17) points out, this type of metonymy cannot be seen as a neologism. In other words, we do not have a new lexeme table that denotes a kind of human. The use of walkouts in example $(1)^{2}$ is, however, best explained in these terms. Here we have a lexeme which is intended to denote a class of human that leaves a restaurant without paying.

While in this paper the discussion of metonymy is restricted to its use in a referring expression, it is worth noting that there are other types of metonymy that are not referential, such as INSTRUMENT FOR ACTION metonymy (e.g., everytime I try to hammer a nail... I hit my finger instead $)^{3}$ but also differences related to the grammatical unit. In addition to referential metonymy, Littlemore and Tagg (2018) outline propositional metonymy, illocutionary metonymy, and situational metonymy; however, space does not

2 This example is given in original orthography.

3 Example from Sketchengine enTenTen15. 
permit a discussion of these different types. For a useful overview of various ways in which metonymies can be classified by type, see Ruiz de Mendoza Ibáñez and Díez Velasco (2002). The definition of referential metonymy that is adopted in this paper is from Bowerman (2016: 2), who states that it involves “a speaker's intentional use of an expression to refer to an entity that does not fall under the literal denotation of the expression". As shown in example (1), the denotation used is that of table, but the entity referred to by the speaker is not a member of that class. Referential metonymy, therefore, involves the use of metonymy in a referring expression. How this differs from metaphor is discussed later in this section.

The role of context is very important since it provides a source for the metonymy. In example (1), it is the customer at a table that the server is responsible for, but the referent is that of the anonymous person who sat at the table, ordered, and ate the food at a given table. This is very similar to the ham sandwich example discussed above. As Bowerman explains (2016: 13), "the referent in the 'ham sandwich' case belongs to the class of restaurant customers; for all members of that class, their food order is (in the restaurant context) a useful identifying property". Therefore, context, either situational or cultural, provides regular and efficient sources for the purposes of referring; however, the options here tend to be in contrast to the wider, or typical, cultural classification of the entity (i.e., table or sandwich for person). This point will be taken up below in section 4 in terms of the SFL concept of congruence.

Metonymy is generally seen as efficient since the referring process is being facilitated rather than being impeded or inhibited. A very basic addressee model (cf. Wilkes-Gibbs \& Clark, 1992) must play a role here and the speaker's anticipated knowledge about what information the addressee has access to is important. In example (1), had the speaker used a typical denotation such as person, man, woman, or customer, e.g., recently a person I served left without paying, the addressee would have managed to ratify the referent without difficulty, i.e., an unidentifiable person 
did not pay. However, the main issue in the text is about not being paid and who is responsible. It is not about that one person. The use of metonymy here has multiple advantages, textually speaking. It allows the speaker to use an expression that brings certain features, aspects, or information into focus (cf. Warren (2004) work on focusing role of metonymy). This would suggest that the use of metonymy serves a textual function. An important question then is what feature or property should be selected. Clearly in the text given above in example (1), using the food item eaten would not have worked, as shown in invented examples (2a-c).

(2) a. I am working in a restaurant and recently the ham sandwich left without paying.

b. I am working in a restaurant and recently one of my ham sandwiches left without paying.

c. I am working in a restaurant and recently a ham sandwich left without paying.

The interesting aspect of using table rather than anything else is that it makes salient the set of potential referents and allows the speaker to select an indefinite instance from that set (cf. reference mass, e.g., Radden, 2009). Bowerman (2016: 4) highlights this point as follows:

[T] he inherent salience of a property does not guarantee its usefulness in every situation. For example, if the situation demands economical-efficient identification of a target entity, the most relevant property of the entity will be one which, regardless of whether or not it is inherently salient, is individuating, i.e. in the context, uniquely picks out the entity without introducing any referential ambiguity which would require extra processing effort to resolve.

Therefore, the fundamental difference between the ham sandwich example and example (1) is that the referring expression in the ham 
sandwich is used by the speaker to be uniquely referring (i.e., specific and identifiable), whereas the expression one of my tables is not. We will return to this point in the discussion below.

According to Jiang (2013), there are three cognitive constraints on the use of metonymy: the use of metonymy is contextually bound, i.e., the metonymic expression should be salient in the context; the addressee's knowledge of the context should be considered; and the metonymic expression should minimise the cognitive effort but maximise the cognitive effects in the conversation. The first two 'constraints' are in fact shared with typical referring expressions. It is well-established that referring expressions are contextually-bound and that speakers make selections in producing a referring expression taking into account the addressee's knowledge. However, to the best of my knowledge, the third aspect has not been considered in general in relation to referring expressions broadly speaking. Perhaps one exception is computational work on referring expressions (Dale \& Reiter, 1995), which considers Gricean principles and how they relate to referring. It is perhaps reasonable to assume that, in typical language use, we should expect that referring expressions will generally adhere to a principle of minimizing cognitive effort while maximizing cognitive effects.

Before ending this overview of metonymy, we will consider some examples of referential metonymy which differ from those discussed above in that they involve the use of a proper name rather than a shift in denotation. Here we will consider examples of the use of the proper name Canada. Typically, the use of Canada as a proper name would be expected to refer to the land mass that is geographically and politically identifiable. Proper names are, typically, used by speakers to uniquely refer, i.e., to refer to a uniquely identifiable referent. However, Dancygier (2009: 168) presents a convincing case for the rich contextual frames represented by proper names. In examples (3) to (7), the highlighted instance of Canada is being used to refer to very different entities in each case. In example (3), it is clear that it cannot be the case that Canada, as a land mass, signed the deal since only people can sign the deal. 
This type of metonymy is different from what was discussed above since it does not involve a shift in denotation but rather in type of referring expression. Examples (4) and (5) are very similar in this regard. The same proper name is used, but again the discourse referent is different in each case. However, what is shared in these cases is a potential to open up the referential potential. As explained by Cislaru (2007: 108) "metonymy more than doubles the number of possible referential and topic developments". We might say that it introduces a semantic junction (see section 4 below). In example (3), we can see that both spatial reference and institutional meanings are accessible. In example (4), we also find both place and institution construed. For Cislaru (2007: 102) the use of placename metonymy can be seen as "a cognitive and pragmatic tool, putting reference at the service of the topic". We also find multiple meanings construed in example (5), with place and team meanings, but not institutional. The team semantics are reinforced textually by the anaphoric use of them later in the sentence.

(3) With little time left ahead of a deadline to agree to a renewed NAFTA trade deal, Canadian and us officials on Sunday tried to settle differences on tough issues such as protection against us tariffs. The Trump administration said Canada must sign onto the text of the updated North American Free Trade Agreement by midnight ET on Sunday or face exclusion from the pact, which includes Mexico.

(The Guardian, September 30, 2018)

(4) Just four months ago in Quebec, a runaway train carrying 72 cars of crude oil killed 47 people and demolished the town of Lac-Megantic. [...] In the aftermath of this accident, Canada issued an emergency directive requiring a minimum of two-person crews for trains carrying hazardous materials.

(Transportation Trades Department, October 29, 2013)

(5) But in the 19 Olympic and World Championship final games since womens [sic] hockey arrived on the international stage in 1999, it has 
been Canada against the United States 18 times. Canada begins by facing Switzerland on Saturday at 8:00 a.m. in their first game of the tournament - watch it live on CBC TV and streaming at cbc.ca/olym pics. The mere fact Canada has won the past three of four gold medals at the Olympics - losing only in Nagano in 1998 - would make them the favorites in the eyes of many.

(SketchEngine, enTenTen15)

If we consider the examples in (6) and (7), we find some significant differences. For example, these instances of Canada do not carry an institutional sense. According to Cislaru (2007: 108), "country-name based metonymies preserve the spatial reference, place being an unalienable element of the holistic concept". What we see in these two examples is the spatial reference, but it seems that the institutional reference is suppressed, due perhaps to the shift in the lexicalisation of Canada from proper name to noun with denotation, e.g., my Canada, Trudeau's Canada. Here Canada is used as a common noun which denotes a class, i.e., my Canada allows for more than one Canada and, therefore, is construing a class of thing that can be denoted by Canada that has members that are types of Canada and excludes those that are not. Dancygier has shown that proper names used in this manner are not uniquely referring as would be expected, but rather they "activate a unique frame of knowledge associated with the name in question" (2009: 166). The effect of a possessive determiner in these instances contributes, according to Dancygier, "an experiential or attitudinal perspective of a specific individual" (2011: 231). We might, therefore, paraphrase examples (6) and (7) as X's version of Canada.

(6) Being a Canadian means different things to different people. I am proud to be a Canadian because my Canada is about inclusion.

(My Kawarta, June 30, 2011) ${ }^{4}$

4 Retrieved from https://www.mykawartha.com/opinion-story/3686565-my-can ada-includes-everyone 
(7) Trudeau's Canada has plenty of critics, too.

(Academy of Ideas, 2017)

It could be tempting to account for these instances as metaphorical uses of Canada, but there is an important distinction to be made between metonymy and metaphor. As Peirsman and Geeraerts (2006: 271) explain, metonymy is seen as "a shift within one domain; metaphor is a shift across domains". While there is a clear shift with referential metonymy, there is no transfer of domain. This difference is highlighted by Barnden (2010: 12) as follows:

It might be claimed that in metaphorical similarity there is no real source-side entity corresponding to the target-side entities, whereas in metonymy there is. For example, metaphorically casting a person Richard as a lion does not involve a particular, real lion, whereas metonymically referring to some real artworks via an artist does involve the artist being real as well.

In the above examples, there really is a ham sandwich, a table, and a Canada. In these cases, intra-domain shift seems to be an important feature of referential metonymy, seemingly dependent on it and very much anchored in its context of use. Considering this perspective on referential metonymy, the work of Martin (1992) on discourse semantics, within the context of text semantics and his IDENTIFICATION system, provides an inspirational source for exploring the textual resources for referring.

\section{Martin's IDENTIFICATION system}

From the discussion of referential metonymy above, it is clear that context plays an important role. In each instance of referential metonymy, we find a referring expression that is either presented

5 Retrieved from https://www.battleofideas.org.uk/2017/session/trudeaus-cana da-a-liberal-nirvana/ 
as a new referent, i.e., not previously mentioned in the discourse or recoverable, or it is presented as a recoverable reference, one that is known or recoverable from the discourse or context. Martin's (1992) system network of IDENTIFICATION represents the (discourse semantic) resources for participant identification. In other words, it describes the set of resources, from a textual perspective, for introducing a participant into the discourse and maintaining the participant once there.

Figure $1^{6}$ summarizes the main features of the IDENTIFICATION system, adapted from Martin (1992). The entry point to this system is participant, which Martin defines as "a person, place or thing, abstract or concrete, capable of functioning as Agent or Medium in TRANSITIVITY" (1992: 129). As Martin explains, this use of participant as a term comes from a stratificational framework (e.g., Gleason, 1968) and it does share some overlap with Halliday's term participant or participating entity (see Halliday, 1976: 160). For Martin (1992: 129) "all participants are realised through nominal groups but not all nominal groups realise participants and some nominal groups realize more than one". This suggests that the term captures what would be referred to as a (discourse) referent in many other theoretical frameworks. Some nominal groups do not have reference (e.g., it's raining, if we consider it as a nominal group) and some nominal groups realise more than one participant, e.g., John's son, given that this nominal expression refers to both John and another participant son. For Halliday, the term participant is typically used in relation to process in the TRANSITIVITY system. Participants are typically realized by nominal groups, but even when a nominal group encodes two different discourse referents, the nominal group would be said to be realizing one participant at clause rank. For example, in John's son is kind, the nominal

6 Note that this figure includes a correction of the error in the original where the features 'nominal' / 'pronominal' are seen as further distinctions of the unique feature whereas it is clear from the discussion (see Martin 1992: 111) that this set of options must stem from the feature variable. 
group John's son is represented as Carrier in an attributive relational process (see Halliday \& Matthiessen (2014) for more detail on transitivity). Martin and Halliday are not saying very different things, but instead they are using the term participant in slightly different ways and for different purposes.

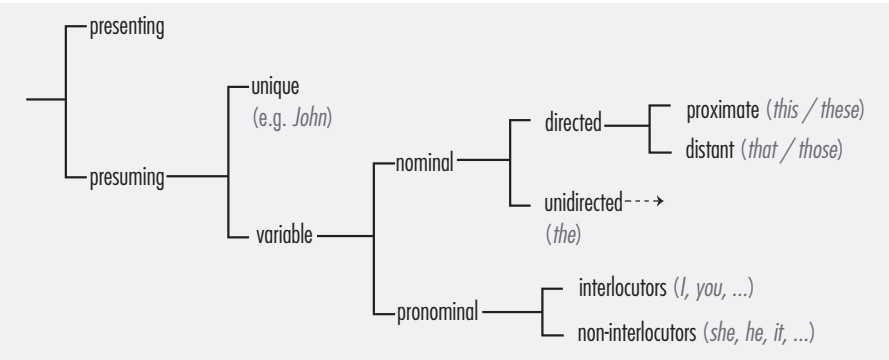

Figure 1. Martin's IDENTFICATION system (adapted from Martin, 1992: 112)

From Figure 1, we find a major distinction in the IDENTIFICATION system between presenting and presuming, where the identifiability of the participant is seen as either recoverable (presuming) or not recoverable, i.e., new (presenting). Recoverability, or what Martin calls phoricity, involves relating "phoric items to their context by way of presumed information" (Martin, 1992: 121). In terms of the examples discussed above, we saw that the ham sandwich is a referring expression that identifies the participant as presumed, i.e., the speaker presumes that the addressee has the information to identify the intended participant. This is signaled through the use of the definite determiner, the, which is inherently phoric. In contrast, example (1) involved a participant which was realized as new, i.e., the speaker assumes the addressee will not be able to identify the intended participant and indeed is indicating to the addressee that it is not necessary for the current discourse purposes. Here one of signals an indefinite reference similar to the use of $a$ or any (e.g., when/if any of my tables leave without paying...).

The use of proper names such as Canada, however, is quite different from both pronoun use and from the use of nominal group 
resources. For example, names have no experiential content but, as Martin points out (1992: 121), "referring to participants by name opens up an important set of interpersonal resources particularly sensitive to tenor". In terms of reference, names are well established in all approaches to referring expressions as being uniquely identifying. Therefore, the use of a proper name suggests that the speaker presumes the referent is identifiable. There is no scope here for a thorough discussion of proper names, but see Klassen (2018) for a detailed account that challenges some of the existing assumptions underlying the referential status of proper names. For our purposes, it suffices at this point to simply consider how the use of proper names is seen as presuming and unique as opposed to variable.

In Martin's framework, proper names are a type of homophoric reference. For Martin (1992: 122), homophora involves a presuming identification that is due to "interlocutors' membership in a particular community". Proper names fall into this category, as do referents such as the sun or the dog, as in have you fed the dog? (see Martin (1992) for further details). There is an assumption made here about the use of proper names and that there is a given and established reference between the use of the proper name and a unique and identifiable referent. To return to the examples of Canada discussed above, it should be clear that this is not always the case. In other words, we must also be able to account for non-literal or non-typical uses of proper names.

It is important to keep in mind that Martin's use of participant is the entry point or condition for the IDENTIFICATION system and that this system is situated within discourse semantics, i.e., part of the semantics stratum, whereas the nominal group is part of the lexicogrammatical stratum. As Martin (1992: 129) explains, IDENTIFICATION and nominal group structure operate on different strata; "the IDENTIFICATION system has been stratified with respect to nominal group structure". It is through this system that we are able to explore "reference as semantic choice" (Martin, 1992: 93). 
This approach seems very relevant to the discussion above on referential metonymy. The gain or benefit from a stratified framework is explained by Martin (1992: 17) as follows:

The level of grammar can be used to provide an interpretation of the "literal" meaning of metaphorical structures and the meaning of congruent ones; the level of semantics can then be deployed to construct additional interpretations for metaphorical expressions (their "figurative" or "transferred" meaning).

What I am suggesting here is that referential metonymy construes incongruent meanings in a way that may be quite similar to, if not a type of, grammatical metaphor.

\section{Grammatical metaphor}

According to Taverniers (2019: 64), "[t]he concept of grammatical metaphor intrinsically has to do with the lack of a one-to-one relationship between meaning and form". Following on from the discussion in the previous section concerning the stratification of the IDENTIFICATION system from the nominal group, we can now consider how referential metonymy opens up a semantic space between meaning and form such that there is, in these instances, no longer a one-to-one relationship. Taverniers' work shows how stratification generally makes it possible to create meanings in ways that the language system could not otherwise. According to Taverniers:

[S]tratification makes it possible to create meanings that are adapted to specific contexts and that are beyond what is (fixed or 'codified') in the (lexicogrammatical) system of a language. Stratification makes it possible to use forms in ways that go beyond their valeurs in lexicogrammatical systems, for instance to mean several things at the same time, i.e. to be creative in a 
myriad of ways with the finite means that are available in the formal units of the language (Taverniers, 2019: 63).

It may now be clear that the position taken in this paper is that we must be able to account for the variability of the referring expressions involved in referential metonymy and, in particular, in the use of proper names. Taverniers (2019: 62) argues that "the stratification of the content plane into semantics and lexicogrammar makes it possible to account for variability between contents and expressions". We will return to this below when we consider whether or not stratification can account for the variability of the use of Can$a d a$ and the other examples of referential metonymy considered in this paper. Before doing so, it is worth considering the SFL approach to congruence and its relationship to grammatical metaphor.

In SFL, congruence is used to describe a type of relation between lexicogrammar and semantics, each represented as different strata in the model and where the role of stratification becomes important (see above). For Martin (1992: 261), "a congruent relationship is one in which the relation between semantic and grammatical categories is natural: people, places and things are realized nominally, actions are realized verbally, logical relations of time and consequence are realized conjunctively, and so on." The idea that underpins this concept is that there is a congruent, or typical, relationship between the units of the lexicogrammar (e.g., nominal group, clause) and the semantics. According to Hansen \& Hansen-Schirra (2012: 135) "“Congruent' refers to a direct and transparent mapping from semantic onto grammatical categories, for example processes onto verbs, entities onto nouns, qualities of an entity to an adjective, etc., whereas other 'indirect' mappings [...] are classified as "metaphorical". For example, as concerns mood, Halliday and Matthiessen (2014: 195) claim that "[f]or statements and questions there is a clear pattern of congruence: typically, a statement is realized as declarative and a question as interrogative". However, once the concept is confronted with empirical data, it is not so clear what relations should be treated as congruent and 
which should not. Steiner (2004: 144) explains that "notions of 'directness' or 'congruence' [are often introduced] as pre-theoretical givens into the discussion [lacking] theoretical motivation and clarification".

Closely related to congruence is construal, a theoretical term with two main uses within SFL (Matthiessen, Teruya \& Lam, 2010: 76): (i) to create meaning in the ideational mode, i.e., construing experience; and (ii) to refer to realization as in "grammatical patterns construe semantic patterns". It is construal then, that gives meaning to the instances of language. For example, an imperative clause such as eat your vegetables, is said to construe a command. It is the process of meaning-making; we might think of it as a kind of inference or interpretation. As Taverniers (2011: 1122) explains, construal refers to "the relationship between language and extralinguistic reality". In relation to congruence, as discussed above, construal is generally used to explain the relationship between semantics and lexicogrammar (cf. realization) in order to specify whether the relation is construed congruently or not. Therefore, anything expressed by a nominal group would, in theory, be being construed as a thing. However, we must ask whether we are saying the same thing if we say that a thing is realized by or is construed by a nominal group. It is certainly clearer if we use realization in relation to congruence/incongruence and leave construal as a separate concept, albeit very much intertwined with both congruence and realization. Wegener (2011: 5) sees realization as having a dialectal relationship with construal and construction. Hasan (2010: 277) explains this relationship as follows: "In the reception of the utterance, realization is construal of the relevant choice at the higher level: thus, in decoding an utterance, the choice in wording construes meaning, the choice in meaning construes context". Here we can see that realization and construal are nearly equated in terms of, in the one sense, relating the wording to the semantics, but we also find simultaneously that the wording construes experience, i.e., is meaning-making in ideational terms. 
A congruent construal is based on an assumption of a typical relation between the wording and the semantics; as a class, a noun construes a thing, i.e., nominal wording (lexicogrammar) typically realizes a participant (semantics); where this is not the case, e.g., where a nominal construes a process, the construal would be said to be incongruent. For Halliday, this is where the concept of grammatical metaphor comes in:

Grammatical metaphor is what turns move into motion, resist into resistance, fail into failure, long into length, can into possible, so ('therefore') into cause (verb or noun). It is metaphor because it involves cross-coupling between semantics and lexicogrammar: an expression is being used to mean something that has usually been meant by something else. (Better: a meaning that has usually been realised in one way is now being realised in another.) (Halliday, 2006: 358, emphasis added)

Halliday explains (2006: 360) that with grammatical metaphor, "the grammar is creating virtual phenomena, phenomena that exist purely on the semiotic plane. This is achieved by a process of semantic junction, whereby two category meanings combine". As we have seen in the discussion above on referential metonymy, there is effectively a blend, in Halliday's sense (2002: 399): where more than one meaning is construed "but the meanings are fused - it is not a matter of selecting one or the other". Although not in these exact terms, an example of this was discussed in (5) above where both spatial and institutional meanings were construed. It is therefore important to examine the potential for the concept of semantic junction and the framework of stratification to account for referential metonymy. It is worth exploring how this resource can be accounted for within SFL.

This pursuit must be left for future work due to space constraints. In the next section we turn to the main concern of this paper, which is to examine the extent to which referential metonymy can be accounted for as a type of grammatical metaphor. 


\section{Referential metonymy as grammatical metaphor}

Given the discussion above, in order for referential metonymy to be a candidate for grammatical metaphor, we would have to first establish the basis for such a claim. As pointed out by Taverniers (2019), grammatical metaphor involves lack of a one-to-one relationship between meaning and form, one that stems from the stratification of semantics and lexicogrammar. In the discussion of referential metonymy above, it was clear that there is a semantic shift and that this shift involves a single domain. Indeed, this is what fundamentally differentiates it from lexical metaphor. Drawing on the semantic system network of IDENTIFICATION (Martin, 1992), there does seem to be an assumed one-to-one relationship between the semantic feature unique and the use of a proper name. However, from examples (3) to (7), it is clear that this is not the case. In fact, what seems to be happening in these examples is that the lexicogrammatical resources (i.e., form) typically associated to the feature unique (meaning) are being used instead to construe the semantics of variable. If we accept this as an example of "a type of a meaning that has usually been realised in one way is now being realised in another" (Halliday, 2006: 358), then we are already beginning to view referential metonymy in a similar way to grammatical metaphor. If this is reasonable, then, what we must ask is what type of grammatical metaphor is at play?

In Section 2 above, I suggested that the use of referential metonymy serves a textual function. There has been relatively little work on textual grammatical metaphor (see Martin, 1992), especially in comparison to the attention given to ideational grammatical metaphor. However, given that these instances all have reference (i.e., are used by a speaker to refer) and they allow the speaker to bring certain properties into focus, it seems natural to consider the incongruence of metonymy as fundamentally textual in nature. There is an argument to be made for the instances that do not involve a proper name such as the ham sandwich and one of my 
tables (see example (1) above). The incongruence noted in these instances is less clearly related to an incongruence between the semantics and the lexicogrammar, but rather in the lexical classification of thing. This denotative shift could seem more related to experiential than textual meaning. It may well be more experiential in the sense that the realization of the Thing element of the nominal group is not semantically congruent with the class of noun selected, i.e., semantic entities that are human are typically expressed by nouns that denote humans, whether as general nouns such as woman, man, person or by profession such as teacher, professor etc. There is an animate/inanimate distinction that is contrasted when a person is referred to as a table or ham sandwich. Experientially, then, we might say that where typically we expect an animate noun as Thing, with some types of referential metonymy, we find an inanimate thing. However, what appears to be motivating this shift is textual in nature; it is a feature of reference and of information focus. It is clear that instances of referential metonymy are expressions that have the potential to form part of a reference chain, i.e., they can be co-referential in a sequence of at least two referring expressions. To illustrate, example (5) presented earlier is repeated here as example (8), where the co-referential items are highlighted in bold and italic. A pronominal anaphoric reference to the geo-political land mass named Canada would be expected to be expressed by the singular pronoun it, but here we have a plural pronoun them, highlighting the individual members of the team as a collectivity, for example they will win or the athletes will win.

(8) But in the 19 Olympic and World Championship final games since womens (sic) hockey arrived on the international stage in 1999, it has been Canada against the United States 18 times. Canada begins by facing Switzerland on Saturday at 8:00 a.m. in their first game of the tournament - watch it live on CBC TV and streaming at cbc.ca/olympics. The mere fact Canada has won the past three of 
four gold medals at the Olympics — losing only in Nagano in 1998

- would make them the favorites in the eyes of many.

(SketchEngine, enTenTen15)

The treatment of referential metonymy in terms of cohesion is not straightforward. Example (8) shows that it is difficult to account for the cohesive relation, and indeed the shared co-reference, without having recourse to grammatical metaphor or at least to some other way of accounting for the atypical realization and the multiple meanings construed. In terms of referring expressions, whether by metonymy or not, it is important to recall that the discourse referent is not in the wording, it is rather a conceptual referent beyond the text. As explained by Rijkhoff (2002: 27):

Noun phrases are referring expressions, but the entities they refer to are not entities in the external physical world. Referents of NPs are rather mental representations of entities as they are created, stored, and retrieved in the minds of the speech participants. [...] Thus a distinction must be made between a referent (mental construct) and its ontological counterpart in the physical world, if it exists.

This idea of the referent as mental construct echoes with the discussion of grammatical metaphor in the previous section. As mentioned above, according to Halliday (2006: 360), grammatical metaphor results in virtual phenomena that "exist purely on the semiotic plane". With metonymic reference we may have evidence for a virtual referent, existing on the semiotic plane and being realized in textually motivated ways, something that has developed due to the stratification of the semantics from the lexicogrammar.

\section{Research directions and concluding remarks}

In this paper, I set out to develop a theoretical position on the place of referential metonymy with an SFL framework. While a case has 
been made for referential metonymy to be accounted for as a type of grammatical metaphor, there are differences marking stark contrasts. We know that referential metonymy is a relatively early development. Falkum, Recasens, and Clark (2017) have shown that children understand and use these metonymies by age 3 . As seen in the discussion in section 2, referential metonymy is generally considered to reduce cognitive load and facilitate reference. From the existing literature, we know that these two features are not shared with ideational grammatical metaphor in its current description. Instances of ideational grammatical metaphor are generally accepted as presenting challenging nominal groups that are difficult for children to process and, therefore, tend to be acquired later, typically restricted to scientific and general academic discourses. Even though referential metonymy is a feature of everyday language, as we have seen here, the semantics are nevertheless complex. Both ideational grammatical metaphor and referential metonymy share a complex semantics that depends on inference. One proposal for the differences between referential metonymy and ideational grammatical metaphor could involve the concrete-abstract continuum. Referential metonymy often involves features that are more salient, more concrete, whereas ideational grammatical metaphor involves features that are less salient, more abstract. Further work is needed to compare these two types of resources, but this will have to be left for future research.

SFL presents a framework that can account for the contextual dependency of these expressions; while I have argued for a theoretical approach that may account for referential metonymy. Drawing on Martin's (1992) IDENTIFICATION system, I have shown that this type of metonymy can be explained through the existing SFL concepts of stratification, congruence, and grammatical metaphor. However, this approach, like all approaches, brings with it certain assumptions that must be examined and tested. Since this paper only considered a small number of examples of only one type of metonymy, a more empirical account is now needed, one which can test the validity of the theoretical proposals I have outlined 
here. Furthermore, given that not all types of referential metonymy draw on the same contextual, situational, or textual resources, future work needs to explore how the contextual variables interplay with metonymy.

There are very few large-scale studies of metonymy (see Littlemore \& Tagg (2018) for an impressive exception to this) and no studies to my knowledge using an SFL approach. In light of this, what I have presented in this paper not only opens up the opportunities to better understand referential metonymy through SFL; it also provides a means of evaluating some of the core concepts within the SFL theory. For example, a key area that should be prioritized involves examining the robustness of the concept of congruence. This is a general issue for SFL, but specifically as concerns referential metonymy, we must ask how we can be confident that the semantic construal is incongruent. Without this, we are riding on assumptions that may be unfounded.

\section{References}

Barcelona, Antono (2019). Metonymy. In Ewa Dąbrowska \& Dagmar Divjak (Eds.), Cognitive linguistics: Foundations of language (pp. 167194). Berlin: Mouton de Gruyter.

BarNDEN, John A. (2010). Metaphor and metonymy: Making their connections more slippery. Cognitive Linguistics, 21(1), 1-34.

BoWERMAN, JosepHINE (2016). Examining the nature of referential metonymy. $U C L$ Working Papers in Linguistics, 28, 1-19.

Cislaru, Georgeta (2007). Metonymic modelling of discourse, discourse modelling of metonymy: The case of the place-name based metonymies. Cultura, Lenguaje y Representación, 5, 93-110.

Croft, Willam (2002). The role of domains in the interpretation of metaphors and metonymies. In René Dirven \& Ralf Pörings (Eds.), Metaphor and metonymy in comparison and contrast (pp. 161-205). Berlin: Mouton de Gruyter. 
Dale, Robert, \& Retter, Ehud (1995). Computational interpretations of the Gricean maxims in the generation of referring expressions. Cognitive Science, 19(2), 233-263.

Dancrgler, Barbara (2009). Genitives and proper names in constructional blends. In Vyvyan Evans \& Stéphanie Pourcel (Eds.), New directions in cognitive linguistics (pp. 161-184). Amsterdam: John Benjamins.

Dancyger, BabBara (2011). Modification and constructional blends in the use of proper names. Constructions and Frames, 3(2), 208-235.

Denroche, Charles (2018). Text metaphtonymy: The interplay of metonymy and metaphor in discourse. Metaphor and the Social World, 8(1), 1-24.

Falkum, Ingrid L.; Recasens, Marta, \& Clark, Eve V. (2017). "The moustache sits down first": On the acquisition of metonymy. Journal of Child Language, 44(1), 87-119.

GLEason, Henry A. (1968). Contrastive analysis in discourse structure. Monograph series on language and linguistics. Georgetown University Round table, 21, 39-63.

Hallody, Michael A. K. (1976). Types of process. In Gunther Kress (Ed.), Halliday: System and function in language (pp. 159-173). London: Oxford University Press.

HalldoAy, Michael A. K. (2002). On grammar and grammatics. In Jonathan Webster (Ed.), On grammar (Vol. 1, pp. 384-417). London: Continuum. Hallday, Michael A. K. (2006). Written language, standard language, global language. In Braj B. Kachru, Yamuna Kachru \& Cecil L. Nelson (Eds.), The handbook of world Englishes (pp. 349-365). Oxford: Blackwell. Hallday, Michael A. K., \& MatTHesSen, Christian M. I. M. (1999). Construing experience through meaning: A language-based approach to cognition. London: Continuum.

Halloay, Michael A. K., \& Mathilessen, Christan M. I. M. (2014). Halliday's introduction to functional grammar. London: Routledge.

Hasan, RuaAly (2010). The meaning of "not" is not in "not". In Ahmar Mahboob \& Naomi Knight (Eds.), Appliable linguistics (pp. 267-306). London: Continuum.

Hansen, Sandra, \& Hansen-SchrRa, Sllvia (2012). Grammatical shifts in English-German noun phrases. In Silvia Hansen-Schirra, Stella Neumann, \& Erich Steiner (Eds.), Cross-linguistic corpora for the study of translations: 
Insights from the language pair English-German (pp. 133-146).

Berlin: Mouton de Gruyter.

Hurford, James R.; Heasley, Brendan, \& Smith, Michael B. (2007). Semantics: A coursebook.

Cambridge: Cambridge University Press.

JIANG, XIAOHONG (2013). Referential metonymy: Reference transfer and pragmatic motivations. UCL Working Papers in Linguistics, 25, 1-20.

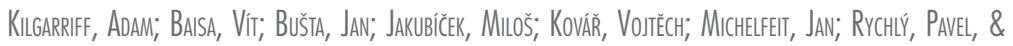

Suchomel, Ví (2014). The Sketch Engine: Ten years on. Lexicography, 1(36), 7-36.

KLASEN, KIMBERIY (2018). Investigating the lexical load of proper names for L2 English readers (Doctoral dissertation). Cardiff University, Cardiff. LAKoff, GEORGE (1987). Women, fire and dangerous things: What categories reveal about the mind. Chicago: Chicago University Press.

Lakoff, George, \& Johnson, Mark (1980). Metaphors we live by. Chicago: The University of Chicago Press.

LangaCKer, Ronald W. (1999). Grammar and Conceptualization. Berlin: Mouton de Gruyter.

Littlemore, Jeannete, \& Tagg, Caroline (2018). Metonymy and text messaging: A framework for understanding creative uses of metonymy. Applied Linguistics, 39(4), 481-507.

MarTiN, JaMes R. (1992). English text: System and structure. Amsterdam: John Benjamins.

Matthilessen, Christian M. I. M.; Teruya, KazuHro, \& Lam, Marvin (2010). Key terms in Systemic Functional Linguistics. London: Continuum.

Pelrsman, Yves, \& Geeraerts, Dirk (2006). Metonymy as a prototypical category. Cognitive Linguistics, 17(3), 269-316.

RadDen, Günter (2009). Generic reference in English: A metonymic and conceptual blending analysis. In Klaus-Uwe Panther, Linda L. Thornburg \& Antonio Barcelona (Eds.), Metonymy and metaphor in grammar (pp. 199-228). Amsterdam: John Benjamins.

RJukHoff, Jan (2002). The noun phrase. Oxford: Oxford University Press Ruiz de Mendoza lañenez, Francisco José, \& Díez Velasco, Olga Isabel (2002). Patterns of conceptual interaction. In René Dirven \& Ralf Pörings (Eds.), Metaphor and metonymy in comparison and contrast (pp. 489-532). Berlin: de Gruyter Mouton. 
Slabakova, Roumyana; Cabrelli Amaro, Jennfer, \& Kyun Kang, Sang (2016). Regular and novel metonymy: Can you curl up with a good Agatha Christie in your second language? Applied Linguistics, 37(2), 175-197.

StenNER, ERcCH (2004). Ideational grammatical metaphor: Exploring some implications for the overall model. Languages in Contrast, 4(1), 137-164. Taverniers, Miram (2011). The syntax-semantics interface in systemic functional grammar: Halliday's interpretation of the Hjelmslevian model of stratification. Journal of Pragmatics, 43(4), 1100-1126.

Taverniers, Miriam (2019). Semantics. In Geoff Thompson, Wendy L. Bowcher, Lise Fontaine \& David Schönthal (Eds.), The Cambridge handbook of systemic functional linguistics (pp. 55-91). Cambridge: Cambridge University Press.

Warren, Beatrle (2004). Anaphoric pronouns of metonymic expressions. Metaphorik.de, 7, 105-114.

Wegener, ReBeKaH (2011). Parameters of context: From theory to model and application (Doctoral dissertation). Macquarie University, Sydney.

Wllkes-Gibss, Deanna, \& Clark, Herbert H. (1992). Coordinating beliefs in conversation. Journal of Memory and Language, 31(2), 183-194. 
